\title{
Prevalence of Obesity and Nutritional Habits Among Primary School Students in Assiut City, Egypt.
}

\author{
${ }^{1}$ Medhat A. Saleh, ${ }^{1}$ Ahmed M Hany, ${ }^{2}$ Treza M. Gad \\ ${ }^{1}$ Department of Public Health and Community Medicine, Assiut University, Egypt, \\ ${ }^{2}$ Primary Health Care Sector, Assiut Health Directorate, Ministry of Health
}

\begin{abstract}
Childhood obesity is a serious medical condition; it has both immediate and long-term effects on health and well-being. Objective: To estimate the prevalence and possible risk factors of obesity among school children. Method: After obtaining an approval from the concerned authority and the local research committee, a community based cross sectional study was conducted in four primary schools in Assiut city. A multistage stratified cluster random sampling technique was applied, in which 838 students were enrolled and distributed among public and private schools of both boys and girls proportionate to number of students in each type of education. Data was collected by semi-structured questionnaire filled by the investigator himself including socio-demographic, nutritional and lifestyle data, weight and height were taken by standardized method from which BMI for age and sex percentiles were calculated for every student, overweight is defined as $\geq$ 85th to 95th percentile, while obesity if $\geq 95^{\text {th }}$ percentile. Results: Overweight and obesity were observed in $14.2 \%$ of students (9.6\% overweight and $4.6 \%$ obese), while underweight in $41.5 \%$. Stunting (low height for age) was observed in $12.8 \%$. We found six risk factors associated with obesity: Fast food consumption (Odds Ratio 5.6), eating between meals (Odds Ratio 4.1), older age (Odds Ratio 3.5), irregular physical activity (Odds Ratio 2.5), number of meals (Odds Ratio 2.1), and lack of eating vegetables (Odds Ratio 1.6), while skipping breakfast meal was not found to be a risk factor. Conclusion: Malnutrition either obesity or underweight are a prevalent nutritional public health problem in primary school students in Menia Governorate.
\end{abstract}

Keywords: Obesity;Prevalence,Primary; School. Egypt.

Corresponding Author: Medhat A.Saleh Email: medhatelaraby75@yahoo.com

\section{Introduction}

Childhood obesity is one of the most serious public health challenges of the 21 st century. The problem is global and is steadily affecting many low- and middle-income countries, particularly in urban settings and the prevalence has increased at an alarming rate. Globally in 2010 , the number of overweight children under the age of five is estimated to be over 42 million, close to 35 million of these are living in developing countries. ${ }^{(1)}$

Overweight and obesity in childhood are known to have significant impact on both physical and psychological health, overweight and obese children are likely to stay obese into adulthood and more likely to develop diseases like diabetes, hypertension, infertility and cardiovascular diseases at a younger age. ${ }^{(2)}$ It is emerging convincingly that the genesis of Type 2 Diabetes and Coronary Heart Disease begins in childhood, with childhood obesity serving as an important factor. ${ }^{(3)}$ Genetic factors influence the susceptibility of a given child to an obesity-conducive environment, however, environmental factors, lifestyle preferences, and cultural environment seem to play major roles in 
the rising prevalence of obesity worldwide. $^{(4)}$

Childhood obesity is a condition which must be taken seriously. It occurs when a child is over the normal weight for his or her age and height. ${ }^{(5)}$ Obesity is a major preventable cause of death worldwide. 600 million adults and 42 million children under the age of five were obese in 2014. ${ }^{(6)}$ Childhood obesity become more evident in recent years as it has more than doubled in children and quadrupled in adolescents in past 30 years. In 2012, A study in the United States showed that children aged 6-11 years who were obese increased from $7 \%$ in 1980 to nearly $18 \% .^{(7)}$

\section{Objectives}

To identify the prevalence and possible risk factors of obesity and study the nutritional habits among primary school students aged 6 to 13 years in Assiut city, Egypt.

\section{Method}

The study is a community based cross sectional study which was conducted in four primary schools in Assiut city, Egypt between January to September 2015.

A total of 1000 student were enrolled and distributed among public and private schools of both boys and girls were included in this investigation. A multistage stratified cluster random sampling technique was applied. Data was collected by semi-structured questionnaire filled by the investigator himself including: Socio-demographic data, Nutritional and lifestyle data, Weight and height were measured by standardized method from which BMI for age and sex percentiles were calculated for every student. Overweight is defined if $\geq 85^{\text {th }}$ to $95^{\text {th }}$ percentile, while obesity if $\geq 95^{\text {th }}$ percentile.

Statistical analysis of the data was done using SPSS version 22.
This is a school based cross-sectional study. The study was conducted in four primary schools in Assiut city that were chosen randomly representing general and private education schools of both sexes in Assiut City. The general education was represented by El-Gamaa school and Emr-Ebn El-Khattab school while the private education was represented by EL-Franciscan primary school and El-Future school, which are mixed schools.

Sample design: A total of 24,746 students were enrolled in all primary schools in Assiut City in 20142015.Target students were selected randomly by using a multistage stratified cluster sampling technique. At the first stage, schools within Assiut city was stratified into 7 districts; which represent 7 different areas in Assiut city to cover all socio-demographic varieties. In the second stage, schools within each area was stratified into 2 strata (general and private education), then at the third stage a cluster sample was chosen from each scholastic year within each school (small classes). The clusters was chosen through simple random sample.

We calculated the sample size according to the equation for the sample size of descriptive study design, and prevalence of obesity $6.9 \%$ in Egyptian children aged 6-12 years ${ }^{(9)} \mathrm{N}=(\mathrm{Z} 1-\alpha / 2) 2 \mathrm{P}(1-$ $\mathrm{P}) / \mathrm{D} 2$

The result was 838 students. We raised the sample to 1000 students to get more informative results and to allow studying different variables related to the problem of obesity. ${ }^{(10)}$

Study population includes students in the primary years of education. The total sample was distributed among general and private primary education schools of both boys and girls proportionate to number of students in each type of education and in the studied schools proportionate to the numbers of the students in each school as follows: 293 
student in Future School, 289 student in El-Franciscan primary school,273 student in El-Gamaea school and 145 students in Omar Ebn El-Khattab.

Data was collected by two techniques: students who can read and write received a self-administered questionnaire under guidance of the researcher and in students who cannot read and write was filled by the researcher. This questionnaire includes: Personal data (name of school, age, sex and father and mother job), data about certain variables related to obesity as physical activity and its regularity (daily or weekly or irregular), data related to dietary habits as number of meals per day, food in between meals (nibbling), eating breakfast, vegetables and fruits in addition to drinking soft drinks and fast food consumption (times of fast food consumption per month) and the anthropometric data about weight and height.

Anthropometric measurements included body weight (in kilograms): It was measured by a standardized balanced digital scale to the nearest 0.5 kilogram, with the student standing on the center of the scale calm and straight without touching anything. ${ }^{(1)}$ Height (in centimeters): Was measured by a standardized fixed stadiometer fixed vertically on the wall. The student stood without shoes, straight, clam with his back against the scaled board of the stadiometer. ${ }^{(11)}$ BMI for-age and sex percentiles are one of the most reliable, known and useful anthropometric measurements for the assessment of obesity in children and adolescents. ${ }^{(12)}$ The results of the equation were applied separately for every child to the standardized percentile curves for age and sex, then students were classified according to these percentile curves into: underweight, normal weight, overweight and obese. ${ }^{(13)}$ Assessment of stunting among primary school students was done using the equation: Height $=($ age in $\mathrm{yr}$ x 5) +80 . Height for Age Percentile Interpretation: Percentile < 5: Short stature, Percentile $\geq 5$ and < 95: Normal stature, Percentile $\geq 95$ : Tall stature. ${ }^{(13)}$

Statistical analysis of data: Statistical analysis was done by compatible computer using software SPSS version 16 for windows. Frequencies, descriptive statistics, correlation, $\mathrm{X}^{2}$ test, $\mathrm{t}$-test and regression analysis were done. The probability of less than 0.05 was used as cut off point for all significant tests.

Ethical consideration: Informed consent were obtained from the students before filling the questionnaire and the student had the complete choice to refuse or stop filling. No sensitive questions were included in the study. Any faulty habits toward obesity were advised through nutritional education.

\section{Results}

Table (1) shows that $29.3 \%$ of studied students were from Future School, 28.9\% of them from El Franciscan School, $27.3 \%$ of them were from El Gamaea and $14.5 \%$ of them from Omar Ebn ElKhattab School.

Table (1): Demographic and individual characteristics of the studied primary school students in Assiut City, 2015

\begin{tabular}{|l|l|l|}
\hline Characteristics & $\begin{array}{l}\text { No. } \\
(\mathrm{n}=1000)\end{array}$ & $\%$ \\
\hline School name: & & \\
\hline$\bullet$ Future School & 293 & 29.3 \\
\hline$\bullet$ El Franciscan & 289 & 28.9 \\
\hline$\bullet$ El Gamaea & 273 & 27.3 \\
\hline $\begin{array}{l}\bullet \text { Omar Ebn El- } \\
\text { Khattab }\end{array}$ & 145 & 14.5 \\
\hline \hline Sex: & & \\
\hline$\bullet$ Male & 514 & 51.4 \\
\hline$\bullet$ Female & 486 & 48.6 \\
\hline \hline Age & 245 & 24.5 \\
\hline \hline$\bullet<10$ years & 545 & 54.5 \\
\hline$\bullet 10-<12$ years & 210 & 21.0 \\
\hline$\bullet \geq 12$ years & $10.29 \pm 1.51$ \\
\hline \multicolumn{1}{|c|}{ Mean \pm SD }
\end{tabular}




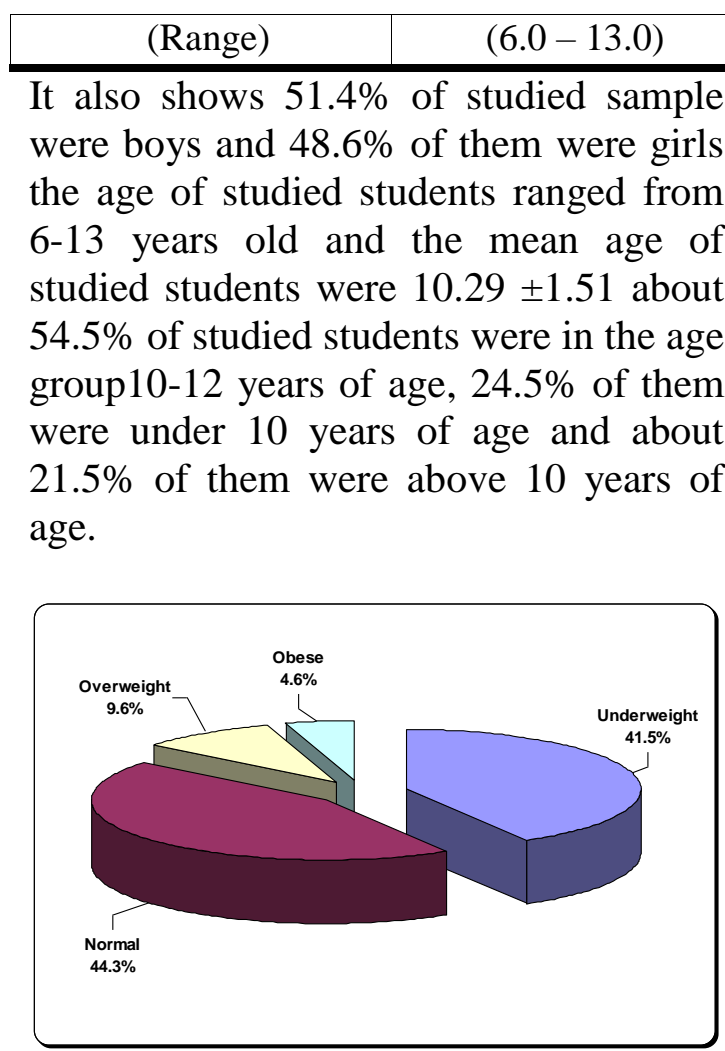

Fig (1): Distribution of the studied primary school students according to weight disorders in Assiut City, 2015

Fig (1) shows that $41.5 \%$ of studied students were underweight, $44.3 \%$ of them were normal, $9.6 \%$ of studied students were overweight and $4.6 \%$ of them were obese.

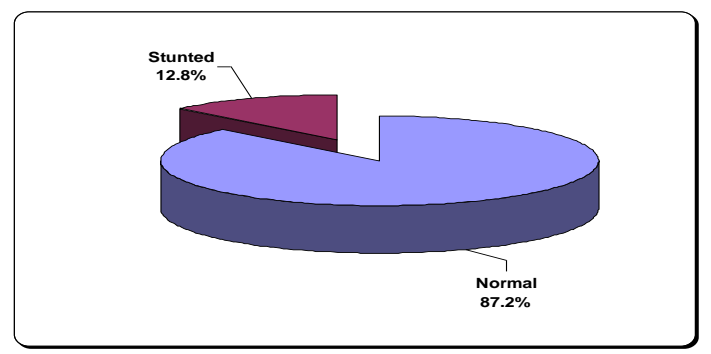

Fig (2): Distribution of the studied primary school students according to height in Assiut City, 2015

Fig (2) shows that $12.8 \%$ of studied students were stunted while $87.2 \%$ of them were of normal height for age which indicate that $12.8 \%$ of studied students complain from chronic malnutrition or stunting.

Fig (3) shows that El-Franciscan and Future schools had the highest percent of obese students (18.3\% and $15.0 \%$ respectively). While Omar Ebn Elkhtab and El-Gamaea schools had lower percent of obese students $(13.2 \%$ and $6.2 \%$ respectively) this difference was highly statistical difference. It also shows that Omer Ebn Elkhtab and ElGamaea schools had the highest percent of underweight students $(60.7 \%$ and $41.4 \%$

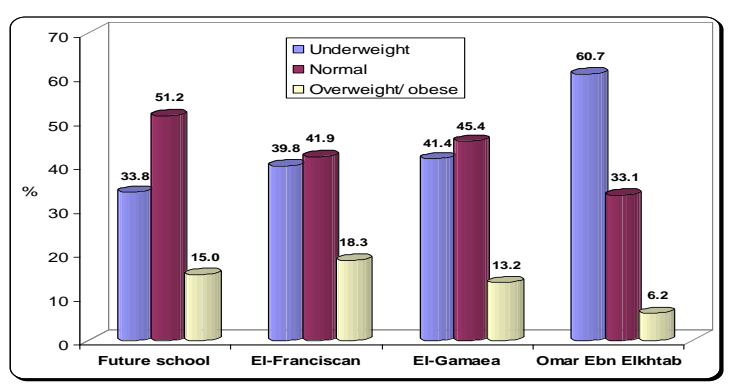

Fig (3): Distribution of weight disorders of the studied primary school students in different schools in Assiut City, 2015 respectively). while El-Franciscan and future school had lower percent of underweight students $(39.8 \%$ and $33.8 \%$ respectively)

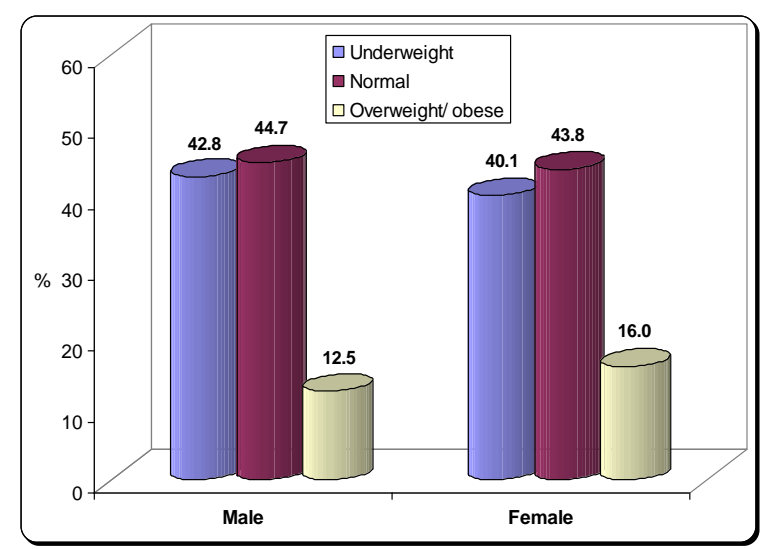

Fig (4): Distribution of weight disorders of the studied primary school students by sex in Assiut city, 2015

Fig(4) shows that $16 \%$ of studied girls were overweight or obese while $12.5 \%$ of studied boys were obese. This difference was not statistically significant (0.252). It also shows that

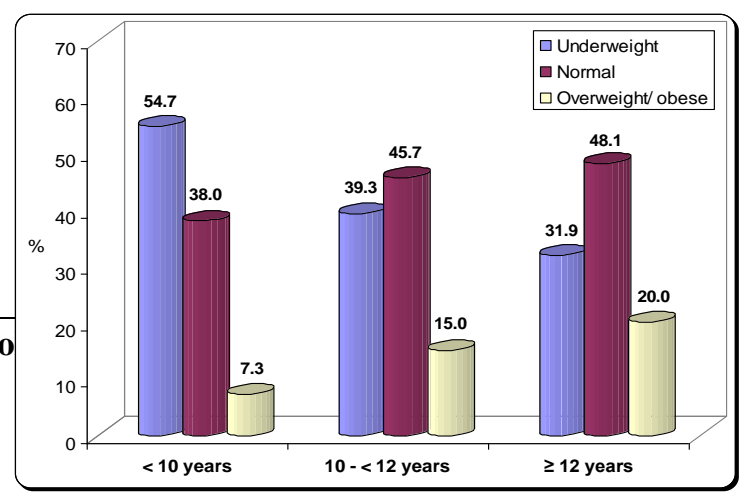


underweight and normal weight students Fig (5): Distribution of weight disorders of the studied primary school students by age in Assiut city 2015

were nearly similar as $42.8 \%$ of studied boys were underweight and $40.1 \%$ of studied girls were underweight.

Fig (5) shows that the percent of overweight and obese students increase with age as $7.3 \%$ of studied students below 10 years were overweight and obese, $15 \%$ of studied students 10-12 years were overweight or obese and $20 \%$

of studied students above 12 years were overweight or obese while the percent of underweight decrease with age as $54.7 \%$ of studied students below 10 years were underweight, $39.3 \%$ of studied students between 10-12 years were underweight and $31.9 \%$ of studied students above 12 years were underweight.

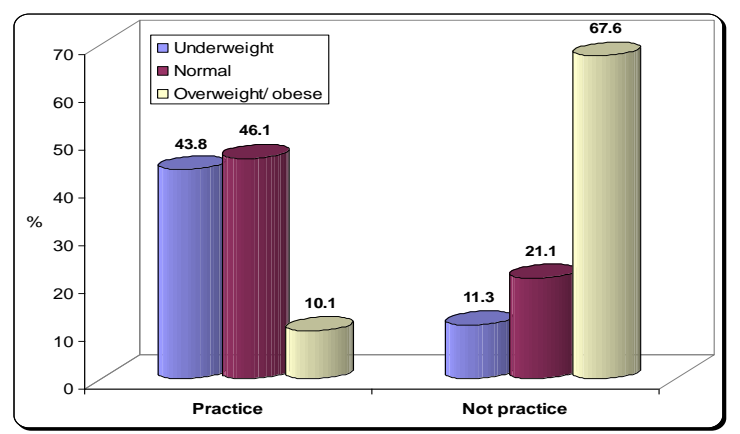

Fig (6): relationship between weight disorders and physical activity practice in the studied primary school students in Assiut City, 2015

Fig (6) shows that $67.6 \%$ of studied students non practicing physical were overweight and obese, $21.1 \%$ of them were normal weight and $11.3 \%$ of them were underweight while $10.1 \%$ of students practicing physical activity were overweight and obese, $46.1 \%$ of them were normal weight and $43.8 \%$ of them were underweight.

Fig (7) shows that the commonest nutritional habit of overweight and obese students was fast food consumption $(80.7 \%)$ followed by eating more than 3 meals per day $(65 \%)$ followed by drinking soft drinks (26.8\%) while the commonest nutritional habit of normal weight students was eating vegetables $(52.3 \%)$ followed by eating breakfast $(51.8 \%)$ while the commonest nutritional habit of underweight students was eating 3 meals or less.

Fig (7): Relationship between nutritional habits and obesity among the studied primary school students in Assiut City, 2015

Fig (8): Correlation between age of the primary school students and BMI of them in Assiut City, 2015

Table (2): Multivariate analysis for risk factors of obesity among the primary school students in Assiut City, 2015

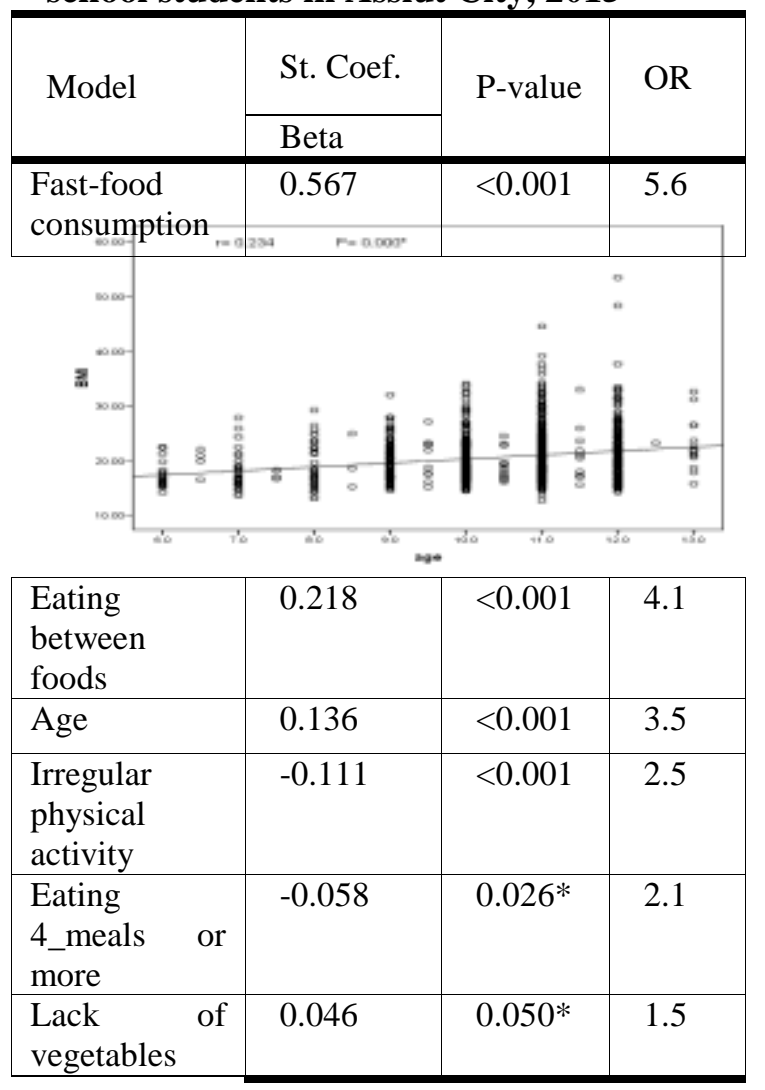

As shown in fig (8) there was positive and very highly significant correlation $(p=0.000)$ between age of the students and BMI of them indicating that obese and overweight students increase with

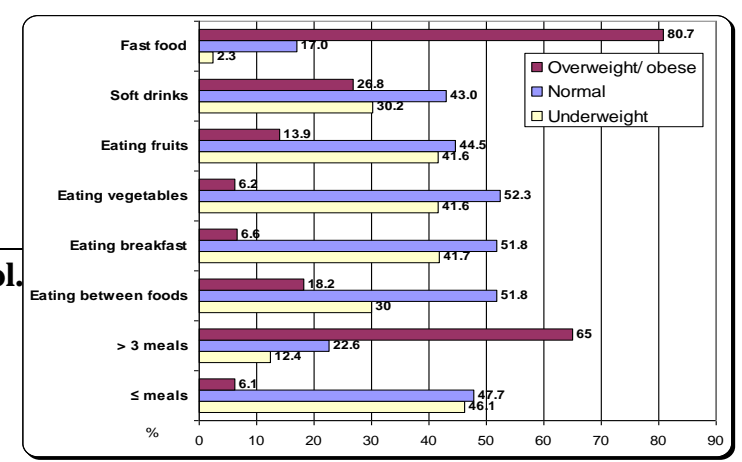


increase age of students.

Table (2) shows that there was 6 risk associated with the development of obesity among the primary school students in Assiut City, the most contributing risk factor for obesity of these 6 risk factors was fast food consumption (Beta $=0.567 \& \quad \mathrm{p}=0.000$ ) then eating in-between meals (Beta $=0.218 \& \mathrm{p}=0.000$ ) and the least contributing risk factor was lack of eating vegetables $($ Beta $=0.439 \quad \&$ $\mathrm{p}=0.50$ ).

\section{Discussion}

The current study showed that the prevalence of obesity among the primary school students in Assiut city was $4.6 \%$, while the overweight students (pre-obese or at risk of obesity) were slightly more than the obese students constituting 9.6\% of the students. So overweight and obese students constituted $14.2 \%$ of the studied sample, those of normal weight constituted less than half of the students $(44.3 \%)$ and underweight students represented $41.5 \%$ of the students.

We observe from our results that the problem of underweight is still prevalent nutritional problem in children in Upper Egypt as mentioned by the National Nutrition Institute, 2003, ${ }^{(9)}$ that reported the double burden of obesity and malnutrition is clearly evident. These results go in consistence with Osman M Galal, 2002, ${ }^{(14)}$ who studied nutrition transition in Egypt and found that $16.7 \%$ of 2-6 year-old children and 7.4\% of 610 year-old children were underweight. On the light of our results, the problem of overweight and obesity seems to be prevalent together with the problem of underweight in Assiut City. We observe in this study that underweight students are more prevalent in general schools than in private schools this may be due to economic factors

In our study we found that the prevalence of stunting, low height for age, which is a measure of chronic malnutrition among children in Assiut City were $12.8 \%$ that go in consistence with Justine A. Kavle, $2013,{ }^{(15)}$ who studied factors associated with the rise in stunting in Lower Egypt in comparison to Upper Egypt that found that stunting in Lower Egypt rise from $19 \%$ to $36 \%$ in 2005 and 2008 respectively. This can be explained by decrease in children intake of proteins and increased intake of sweets and chips which became easily obtained by children.

In our study we found that the prevalence of obesity among children in Assiut city is nearly equal to that stated by the National Nutrition Institute, 2003, ${ }^{(9)}$ that reported the prevalence of obesity among all Egyptian children as $6.9 \%$ in 6-12 year-old children.

In our study we found that obesity and overweight was more prevalent among girls (16\%) than boys (12.5), this results go in consistence with a study done in Egypt by the National Nutrition Institute, $2003,{ }^{(9)}$ that found that overweight and obesity were prevalent among female children (6-12 years) at a double rate than that of male children (prevalence of obesity in female children 6-12 years was $4.5 \%$ while in male children it was $2.4 \%$ ). This may be due to decreased physical activity of female students than male students.

In our study we found that obesity increase with age as $20 \%$ of students above 12 years were overweight or obese compared to $15 \%$ of students between $10-12$ year and $7.3 \%$ of students below 10 years of age that go in consistence with national institute of diabetes and digestive and kidney diseases, 2010, ${ }^{(16)}$ shows that among people ages 2-5 years $12.1 \%$ had obesity, among people ages 611 years $18 \%$ had obesity and among people $12-19$ years $18.4 \%$ had obesity. That can be explained by decline in physical activity by age.

In the present study, obesity was found to be more prevalent in private schools than in general schools, this finding is in 
agreement with M. Shih et al, 2012, ${ }^{(17)}$ who studied the relationship between economic level and obesity among school children in Los Angeles and found that there was a strong correlation between prevalence of childhood obesity and economic hardship across the 135 defined communities in Los Angeles. The prevalence of obesity among communities ranged from $4.2 \%$ to $40.0 \%$. The community with the lowest economic level had an obesity prevalence of $6.6 \%$, while the obesity prevalence in the community with the highest economic level was more than four times higher $(28.8 \%)$. This finding go inconsistence with a study done in India by Preetam B Mahajan et al, 2011, ${ }^{(18)}$ that found that prevalence of overweight and obesity was $2.84 \%$ and $1.82 \%$ respectively among children in general schools, whereas it was found to be higher among children studying in private schools, being $6.23 \%$ and $2.48 \%$ respectively. Children from private schools were 1.71 times and 1.06 times at greater risk of being overweight and obese, respectively, compared to children in Governmental schools. These findings suggest that children belonging to relatively higher socioeconomic level who are likely to study in private schools, are at higher risk of obesity, mostly due to associated lifestyle changes leading to increasing levels of physical inactivity and inappropriate diet. Physical inactivity may contribute to the development of obesity in the community and a decline in physical activity means that those who are susceptible to weight gain will be at risk of becoming obese. Our study showed that there is a very highly statistically significant inverse relationship between physical activity and obesity $(\mathrm{P}<0.001)$, as $67.6 \%$ of the overweight and obese students did not practice physical activity compared to $21.1 \%$ of the normal weight students.
This finding is in agreement with Trost SG et al, 2002, ${ }^{(19)}$ who studied physical activity and determinants of physical activity in obese and non-obese Australia children and found that physical activity level was significantly higher among the non-obese than their obese counterpart, these results are also matched with Berkey et al., 2000, ${ }^{(20)}$ who found that physical activity was inversely associated with BMI changes in preadolescent and adolescent boys and girls.

Based on the results of multivariate analysis, a stepwise regression analysis was done between BMI percentile for age and sex of the students as a dependent factor and the following independent factors, physical inactivity, the dietary habits of skipping breakfast, fast food consumption, number of regular meals eaten by the students per day, eating between meals, lake of eating vegetables and their nutritional knowledge toward obesity.

We found 6 risk factors associated with obesity and they were in order of the strength of association as follows. Fast food consumption (Beta $=0.567 \&$ $\mathrm{P}=0.000)$ then eating between foods, nibbling (Beta $0.218 \& \mathrm{P}<0.001$ ), older age $($ Beta $=0.136 \& \mathrm{P}<0.001)$, irregular physical activity $($ Beta $=0.111 \&$ $\mathrm{P}<0.001$ ), the dietary habit of eating 4 meals or more (Beta $=0.058 \& \mathrm{P}=0.026$ ), while the least contributing risk factor was lack of eating vegetables (Beta = $0.046 \& \mathrm{P}=0.05)$. While the dietary habit of skipping breakfast and the nutritional knowledge toward obesity were not found to be risk factors for obesity.

Our results are different from a study done in Abu Dhabi, United Arab Emirates by A Al Junaibi et al.,2012, ${ }^{(21)}$ where Stepwise linear regression of BMI percentile on age, sex, dairy consumption, exercise and family income was done and showed a significant $(\mathrm{P}<0.01)$ positive association with age and lack of dairy consumption, but not exercise and income. This 
difference in results may be due to absence of dietary habits in the second regression study but age appears to be important factor in both studies as prevalence of overweight and obesity increases with increase age that can be explained by decline in physical activity and increased fast food consumption by age.

\section{Conclusion}

Our study showed that $4.6 \%$ of the students were obese and $9.6 \%$ of them were overweight while $41.5 \%$ of them were underweight. Dietary habits of eating more than 3 meals per day, eating in-between meals, consumption of soft drinks and juice, fast food consumption and skipping breakfast have a significant relationship with the development of obesity in the primary school students in Assiut City.

We found that the following are very important risk factors for development of obesity among the primary school students in Assiut City. Risk factors were fast food consumption, eating between meals, increase in age, eating 4 meals or more and lack of eating vegetables.

\section{Recommendations}

Obesity should be viewed as a very serious medical problem especially in children and its prevention should begin as early as possible and on the lights of our results we recommend a national program to prevent and treat obesity should be developed as soon as possible and all the community should share in its implementation. Fast food consumption should be restricted in children and adolescents and not easily available to them. Parents should learn more and more about the healthy diet and its constituents and should be advised to monitor the dietary habits of their children and correct any bad habits of their children as early as possible.

\section{References}

1. Sahoo K., Bishnupriya S., Ashok K. C. et al. Childhood obesity: causes and consequences. J Family Med Prim Care. 2015 Apr-Jun; 4(2): 187-192.

2. Gupta R. K. Nutrition and the Diseases of Lifestyle. In: Bhalwar RJ, editor. Text Book of Public health and Community Medicine. 1st ed. Pune: Department of community medicine AFMC, New Delhi: Pune in Collaboration with WHO India Office; 2009. p. 1199.

3. Bhave S., Bavdekar A., Otiv M. IAP National Task Force for Childhood, Prevention of Adult Diseases: Childhood Obesity. IAP National Task Force for Childhood Prevention of Adult Diseases: Childhood Obesity. Indian Pediatr. 2004;41:559-75.

4. Badawi N. E., A. Abo Barakat, S. A. El Sherbini: Prevalence of overweight and obesity in primary school children in Port Said city. Egyptian Pediatric Association Gazette, V. 61, Issue 1, January 2013, Pages 31-36 .

5. CDC, (2013): About BMI for children and teens. Centers for Disease ControlandPrevention.http://www.cdc.gov/ healthyweight/assessing/bmi/childrens BMI/about children BMI.html. Accessed Sept 25-2013

6. WHO, (2015):"Obesity and overweight Fact sheet $\mathrm{N}^{\circ} 311 "$. WHO gden CL, Carroll MD, Kit BK et al, (2014): Prevalence of childhood and adult obesity in the United States, 2011-2012. Journal of the American Medical Association 2014;311(8):806-814.

7. Ogden CL, Carroll MD, Kit BK et al, (2014): Prevalence of childhood and adult obesity in the United States, 20112012. Journal of the American Medical Association 2014;311(8):806-814.

8. Egypt Demographic Health survey EDHS, (2014): Ministry of health and population, Cairo, Egypt The DHS Program ICF International Rockville, Maryland, U.S.A.29-32

9. National Nutrition Institute, (2003): Prevalence of obesity in Egypt, Public health bulletin; 33 (4); 895-926.

10. WHO document, (1998): Measuring, Classification and description of obesityanthropometric data. Copenhagen, WHO Regional Office for Europe. WHO, technical report series; 536: 525-678. 
11. Cameron, N (1978): Human growth. In human growth and development. 2nd Ed bailliere Tindall, London. 24:145-157.

12. Seidell, J. C.; Oosterlee, A. and Sato, N. (1998):Time trends in the world wide prevalence of obesity. In: Handbook of obesity, 2nd ed. New York; 13: 50-60.

13. CDC, (2000): Center of disease control, US, Department of Health and Human Services (August 2000). Http: /www. cdc. gov/ growth charts. In 15 January 2003.

14. Osman M Galal, (2002):The nutrition transition in Egypt, obesity, under nutrition and the food consumption cotext. 10.1079/PHN2001286.

15. Justine A.Kavle, (2013):Examining factors associated with the rise in stunting in lower Egypt in comparison to upper Egypt. Bridging the gap between cultural beliefs and feasible feeding practices through Trials for Improved Practices, Washington DC.

16. NIDDK,(2010): National institute of diabetes and digestive and kidney diseases overweight and obesity statistics.http://www.win.niddk.nih.gov /statistics/ index. htm. Accessed oct.2010.
17. M.Shih, K.A. Dumke, M.I. Goran et al,(2012):The association between community-level economic hardship and childhood obesity prevalence in los Angelos. Pediatric obesity. 2012;8(6):4117.

18. Preetam Bmahajan, Anilj Purty, Zile Singh et al,(2011):Study of childhood obesity among school children aged 6 to 12 years in union territory of puducherry. Indian J Community Med .2011; 36(1): 4550.

19. Trost SG, Kerr LM, Ward DS et al,(2002): physical activity and determinants of physical activity in obese and non-obese children. . International Journal of Obesity and Related Disorders; Hampshire 25.6 (Jun 2002): 822-829.

20. Berkey, C.S.; Rockett, H.R. and Field, A., (2000): Activity, dietary intake, and weight changes in a longitudinal study of preadolescent and adolescent boys and girls, Am J Pediatric; 14: 105:156.

21. A Al Junaibi, A Abdulle, S Sabri et al,(2012): The prevalence and potential determinants of obesity among school children and adolescents in Abu Dhabi, United Arab Emirates International Journal of Obesity 37, 68-74; doi: 10.1038/ijo. 2012.131. 